\title{
Implications of Brexit on the effectiveness of the UK soft drinks industry levy upon CHD in England: a modelling study
}

\author{
Paraskevi Seferidi ${ }^{1, *}$, Anthony A Laverty ${ }^{1}$, Jonathan Pearson-Stuttard ${ }^{1,2}$, Maria Guzman- \\ Castillo $^{2}$, Brendan Collins ${ }^{2}$, Simon Capewell ${ }^{2}$, Martin $\mathrm{O}^{\prime}$ Flaherty $^{2}$ and Christopher Millett ${ }^{1}$ \\ 'Public Health Policy Evaluation Unit, School of Public Health, Imperial College London, Reynolds Building, \\ St Dunstan's Road, London W6 8RP, UK: ${ }^{2}$ Department of Public Health and Policy, University of Liverpool, \\ Liverpool, UK
}

Submitted 11 August 2017: Final revision received 11 May 2018: Accepted 13 August 2018: First published online 9 October 2018

\begin{abstract}
Objective: An industry levy on sugar-sweetened beverages (SSB) was implemented in the UK in 2018. One year later, Brexit is likely to change the UK trade regime with potential implications for sugar price. We modelled the effect of potential changes in sugar price due to Brexit on SSB levy impacts upon CHD mortality and inequalities.

Design: We modelled a baseline SSB levy scenario; an SSB levy under 'soft' Brexit, where the UK establishes a free trading agreement with the EU; and an SSB levy under 'hard' Brexit, in which World Trade Organization tariffs are applied. We used the previously validated IMPACT Food Policy model and probabilistic sensitivity analysis to estimate the effect of each scenario on CHD deaths prevented or postponed and life-years gained, stratified by age, sex and socioeconomic circumstance, in 2021.

Setting: England.

Subjects: Adults aged 25 years or older.

Results: The SSB levy was associated with approximately 370 (95\% uncertainty interval 220, 560) fewer CHD deaths and 4490 (2690, 6710) life-years gained in 2021. Associated reductions in CHD mortality were 4 and $8 \%$ greater under 'soft' and 'hard' Brexit scenarios, respectively. The SSB levy was associated with approximately $110(50,190)$ fewer CHD deaths in the most deprived quintile compared with $60(20,100)$ in the most affluent, under 'hard' Brexit.

Conclusions: Our study found the SSB levy resilient to potential effects of Brexit upon sugar price. Even under 'hard' Brexit, the SSB levy would yield benefits for CHD mortality and inequalities. Brexit negotiations should deliver a fiscal and regulatory environment which promotes population health.
\end{abstract}

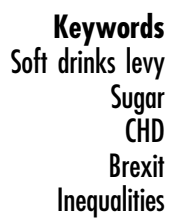

Taxation has been recommended by the WHO as an effective measure to minimise intake of sugar-sweetened beverages $(\mathrm{SSB})^{(1)}$. This is supported by recent evidence from Mexico and Berkeley showing that SSB sales and consumption decreased after SSB taxes were implemented, especially among populations of lower socio-economic circumstance (SEC) $)^{(2-4)}$. Such reductions can have significant health benefits to the population, given the abundance of evidence associating SSB intake with the risk of being overweight or obese $^{(5)}$ and of developing diabetes ${ }^{(6)}$ and $\mathrm{CVD}^{(7)}$. For example, a modelling study suggested that the SSB tax in Mexico would reduce CVD deaths by 10900 over the ten years following its implementation ${ }^{(8)}$.

The UK Government implemented an SSB industry levy in April 2018, as part of its Childhood Obesity Plan ${ }^{(9)}$.
However, the effect of the SSB levy might be affected by the impending exit of the UK from the EU in March 2019, known as 'Brexit'. Brexit is likely to result in a new trade regime, which could range from a free trade regime that eliminates all trade barriers to a default World Trade Organization (WTO) membership that enforces tariffs to all trade relationships.

The trade arrangements that the UK will adopt after Brexit are likely to influence the price of food and food ingredients including sugar ${ }^{(10)}$, which currently follows European regulations under the Common Agricultural Policy. This could potentially interfere with the effectiveness of the SSB levy in the UK. We aimed to estimate the implications of Brexit on the price of sugar and the impact of the implemented SSB levy on CHD mortality and inequalities in England. 


\section{Methods}

We modelled the potential effects of the SSB industry levy on SSB price and consumption and compared it with its effect under a 'soft' and a 'hard' Brexit scenario. We then estimated the effect of the SSB consumption changes on CHD mortality in England in 2021, stratified by age, sex and SEC.

\section{The IMPACT Food Policy model}

We extended the previously validated IMPACT Food Policy model ${ }^{(11-15)}$ to estimate the effect of changes in the price of SSB on CHD mortality and life-years. The model has been validated among adults aged 25 years or above $^{(16)}$ and translates the estimated changes in SSB price into changes in SSB intake, using price effect estimates, and subsequently into changes in CHD mortality, using appropriate relative risks. The policy impacts on CHD were estimated for 2021, the year when the UK plans to officially exit its Brexit transition period and initiate its new relationship with its trading partners. The model assumes a constant effect of the policies over time. All model assumptions are presented in the online supplementary material, Supplemental Table 1.

Changes in CHD mortality were expressed in CHD deaths prevented or postponed (DPP) and life-years gained (LYG). Details on the DPP calculation methodology are presented in the online supplementary material, Supplemental File 1. LYG were calculated as the product of DPP and median survival. A previous modelling study ${ }^{(13)}$ provided age-, sex- and SEC-specific median survival for three population subgroups (diagnosed CHD, undiagnosed $\mathrm{CHD}$, no CHD) and the proportion of CHD deaths in each group.

\section{Data sources}

An overview of the data sources used is presented in the online supplementary material, Supplemental Table 2. To estimate the effect of Brexit on price of sugar, we used 2015 sugar trade data from UK government sources ${ }^{(17,18)}$ and sugar price data from the $\mathrm{EU}^{(19)}$. Further details on trade and price data sources are provided in the online supplementary material.

We obtained CHD mortality (ICD-10 (International Statistical Classification of Diseases and Related Health Problems, 10th revision) codes: I20-I25) data projected to 2021 from Guzman Castillo et al. ${ }^{(20)}$. Those researchers used a hierarchical Bayesian Age Period Cohort (BAPC) model to predict CHD mortality in England and Wales, taking previously declining trends into account. In order to estimate CHD mortality in England only, as well as SECstratified CHD mortality, we used 2013 mortality data available from the Office for National Statistics ${ }^{(21)}$. We assumed that differences in mortality between England and Wales and differences across SEC groups would remain unchanged over time. We stratified the mortality estimates by 10 -year age groups (from 25-34 years to $85+$ years) and sex. We defined SEC using the Index of Multiple Deprivation (IMD), a measure of deprivation in small areas in England (LSOA). For this model, we used quintiles of the 2010 IMD scores, with quintile 1 representing the most affluent areas and quintile 5 the most deprived.

We used results from a meta-analysis of interventional and prospective observational studies that assessed the effect of price change interventions on dietary intake ${ }^{(22)}$, in order to translate SSB price change into SSB consumption. That meta-analysis found that a $10 \%$ increase in the price of SSB was associated with a $6.7 \%$ decrease in their consumption over time. To consider different responses to the SSB price change among SEC groups, we adjusted price effect estimates for SEC using data from an observational study which evaluated the one-year effect of an SSB tax on SSB purchases among three SEC groups in Mexico $^{(2)}$. The price effect estimates used in this model are shown in the online supplementary material, Supplemental Table 3 .

We estimated SSB intake of the study population using data from the National Diet and Nutrition Survey (NDNS) rolling programme, years 1-4 (2008/09-2011/12) ${ }^{(23)}$. This is a nationally representative survey of UK children and adults randomly selected from a list of all UK addresses and uses four-day food diaries to estimate dietary intake. We calculated weighted mean intake by age (20-year age groups from 25-44 years to $65+$ years), sex and IMD quintile among the English population. Due to the small sample size, we combined IMD quintiles 1 and 2, and quintiles 4 and 5, thus calculating estimates for three SEC groups overall.

Finally, to estimate the effect of SSB intake on CHD, we used age-specific relative risks for CHD. Pooled analyses of cohort studies ${ }^{(24)}$ provided BMI-adjusted and BMImediated relative risks for incident CHD by SSB intake (number of servings). We expect that SSB intake would not have any additional effect on the proportion of CHD cases that are fatal, so we assumed a linear relationship between CHD risk and mortality. The overall CHD effect was estimated as the additive effect of a BMI-adjusted and a BMI-mediated effect ${ }^{(24)}$.

\section{Policy scenarios}

We modelled three potential scenarios:

1. SSB industry levy;

2. SSB industry levy under a 'soft' Brexit; and

3. SSB industry levy under a 'hard' Brexit.

The SSB levy is a two-rate industry levy, depending on the sugar content of SSB. A levy of 18 pence ( $\mathrm{p}$ ) per litre is applied to SSB containing 5-8 g sugar/100 $\mathrm{ml}$ and $24 \mathrm{p}$ per litre to SSB containing more than $8 \mathrm{~g}$ sugar/100 $\mathrm{ml}$. Using a weighted average of SSB sales data from 
Table 1 UK trade policy before and after Brexit

\begin{tabular}{|c|c|}
\hline $\begin{array}{l}\text { UK trade policy } \\
\text { before Brexit }\end{array}$ & $\begin{array}{l}\text { As part of the EU, the UK abides by EU trade } \\
\text { policy. This means that it is part of the EU } \\
\text { Single Market and the Customs Union, } \\
\text { being guaranteed free access to the EU } \\
\text { market, benefiting from European Free } \\
\text { Trading Agreements and applying } \\
\text { European external tariffs when trading with } \\
\text { third countries }\end{array}$ \\
\hline $\begin{array}{l}\text { UK trade policy } \\
\text { after Brexit }\end{array}$ & $\begin{array}{l}\text { In a White Paper published in February } \\
2017^{(26)} \text {, the UK Government showed its } \\
\text { intentions to leave the Single Market and } \\
\text { the Customs Union and seek new } \\
\text { preferential trading agreements with the EU } \\
\text { and third countries }\end{array}$ \\
\hline
\end{tabular}

$2017^{(25)}$, we estimated an equivalent pooled singlerate levy.

The two Brexit scenarios assumed that the UK Government will leave the EU Single Market and Customs Union as per its publicly stated negotiating position in February $2017^{(26)}$ (Table 1). We hypothesised that under the 'soft' Brexit scenario the UK will establish a zero duty Free Trading Agreement for sugar with the EU but will trade under WTO regulations with third (non-EU) countries. This means that the UK would have to apply common tariffs to sugar imports from all third countries, including those currently under a Free Trading Agreement with the EU. The more impactful 'hard' Brexit scenario assumes that the UK will take a WTO default position, thus having no preferential trading agreements in place. In that case, the UK would apply WTO tariffs to sugar imports both from the EU and third countries. Under these scenarios, we expect changes in the price of sugar due to increased trade facilitation costs and changes in applied import tariffs. More details on the calculations to estimate the effect of Brexit on price of sugar are presented in the online supplementary material, Supplemental Table 4 and Supplemental File 1.

After estimating the effect of Brexit on the price of sugar, we calculated the potential increase in the cost of $\mathrm{SSB}$, based on the amount of sugar needed for their production. Mean added sugar content of SSB in the UK was estimated using information from brands' websites and UK sales data from Euromonitor International ${ }^{(27)}$.

We combined the SSB levy and Brexit effects to estimate the change in production costs of SSB in $£ / 1$, under each scenario. We then assumed that the industry will pass the cost increase to the consumer on different pass-through rates, which can vary depending on SSB type, retailer and package size ${ }^{(3,28)}$. An observational study in Mexico showed that price pass-through after implementation of an excise tax was $100 \%$ overall, and varied between 36 and $150 \%$ among different SSB products ${ }^{(28)}$. A similar study in Berkeley showed that one year after a tax implementation SSB prices were not significantly changed among some retailers but reached a $220 \%$ pass-through rate among others $^{(3)}$. In the present analysis, we considered three potential price pass-through rates: 80, 100 and 120\%. Finally, we estimated the relative effect of each scenario on SSB consumer price using mean SSB price estimates, calculated from expenditure and purchase data from the Living Costs and Food Survey (2014), a national representative survey of food consumption and expenditure in UK households ${ }^{(29)}$.

\section{Probabilistic sensitivity analysis}

We performed a probabilistic sensitivity analysis to incorporate parameter uncertainty into the model. We used Monte Carlo simulation to repeatedly draw random values of model inputs from their respective statistical distributions. The model inputs that added uncertainty to the model were the sugar imports as a percentage of sugar supply, $€$ to $£$ exchange rate, SSB price, price effect on consumption, mean SSB intake, relative risks, overweight prevalence, CHD mortality and median survival. The distributions used for each input are shown in the online supplementary material, Supplemental Table 5. We conservatively assumed that the model parameters included in the probabilistic sensitivity analysis were independent, when in fact some are likely to be correlated. This may overestimate the uncertainty of the model results. We used the Microsoft Excel add-in 'Ersatz' version 1.35 (EpiGear, Brisbane, Australia) to obtain $95 \%$ uncertainty intervals (UI) from 10000 iterations.

\section{Results}

Effect of modelled scenarios on price of sugar and sugar-sweetened beverages

Imported sugar accounted for $64 \%$ of the total UK sugar supply in 2015. Approximately half of sugar imports to the UK (53\%) came from the EU, while the rest were from third countries, mainly the African, Caribbean and Pacific States. The majority of the third country imports (94\%) were imported under a preferential agreement between the EU and third countries (see online supplementary material, Supplemental Table 6).

We estimated that a 'soft' and a 'hard' Brexit will increase price of sugar by 92 and $203 £ / t$, respectively. With an estimated sugar content of SSB in the UK market at $93 \mathrm{~g} / \mathrm{l}$, we calculated an increase in SSB production costs of 1 and $2 \mathrm{p} / 1$ under 'soft' and 'hard' Brexit scenarios, respectively. The SSB levy would cost the industry $23 \mathrm{p} / 1$ on average. The effect of each scenario on final SSB consumer price under different pass-through rates is shown in Table 2.

\section{Effect of modelled scenarios on intake of sugar- sweetened beverages}

Mean baseline SSB intake in the English population aged 25 years or above was $99.5 \mathrm{~g} / \mathrm{d}$. It varied across age and sex groups, with younger men having the higher intake 
Table 2 Effect of each scenario on the final sugar-sweetened beverage (SSB) price

\begin{tabular}{lccc}
\hline Scenario & Price pass-through (\%) & Change in final SSB price (£/l) & Change in final SSB price* $(\%)$ \\
\hline Scenario 1: SSB industry levy & & \\
Scenario 1a & 80 & 0.19 & 30 \\
Scenario 1b & 100 & 0.23 & 38 \\
Scenario 1c & 120 & 0.28 & 46 \\
Scenario 2: SSB industry levy under 'soft' Brexit & & 32 \\
Scenario 2a & 80 & 0.19 & 39 \\
Scenario 2b & 100 & 0.24 & 47 \\
Scenario 2c & 120 & 0.29 & 33 \\
Scenario 3: SSB industry levy under 'hard' Brexit & 0.20 & 41 \\
Scenario 3a & 80 & 0.25 & 49 \\
Scenario 3b & 100 & 0.30 & \\
Scenario 3c & 120 & & \\
\hline
\end{tabular}

*Assumes mean SSB price of $0.61 £ / /$, estimated using data from the Living Costs and Food Survey $(2014)^{(29)}$.

across all SEC categories. The most affluent group had the lowest SSB intake. Weighted means of SSB intake by age, sex and SEC group are presented in the online supplementary material, Supplemental Table 7.

We estimated that the SSB levy would reduce SSB intake in the overall population by approximately between 21 and $31 \%$ in 2021, depending on the pass-through rate. This estimated reduction varied among SEC groups, under both Brexit scenarios (online supplementary material, Supplemental Table 8). For example, SSB intake in the most affluent group might decrease by approximately $23 \%$ after the levy implementation, compared with $38 \%$ in the most deprived. Under a 'hard' Brexit scenario, the levy could reduce SSB intake by approximately $25 \%$ in the low and middle deprivation groups, compared with $41 \%$ in the most deprived group.

\section{Effect of modelled scenarios on CHD mortality}

CHD deaths in 2021 were projected to be approximately 38000 (95\% CI 30 600, 46 500). CHD mortality was higher among the more deprived populations. Detailed numbers of deaths per each group are presented in the online supplementary material, Supplemental Table 9.

The CHD DPP and LYG estimates for each policy scenario are presented in Fig. 1. In the case of a complete pass-through of the cost increase to the consumer, the SSB levy might save approximately 370 (95\% UI 220, 560) CHD deaths and 4490 (95\% UI 2690, 6710) life-years in 2021. A 'soft' Brexit scenario will save $4 \%$ more CHD deaths (approx. 10 deaths) and life-years (approx. 160 lifeyears) and a 'hard' Brexit scenario $8 \%$ more CHD deaths (approx. 30 deaths) and life-years (approx. 360 life-years) compared with an SSB levy only scenario. The industry response to the cost increase would substantially influence the effectiveness of the policies, as an $80 \%$ pass-through could save $20 \%$ fewer CHD deaths and life-years across all scenarios and a $120 \%$ pass-through $20 \%$ more, compared with a complete price pass-through to the consumer.

People of younger age would benefit the most from the SSB levy under all Brexit scenarios (Fig. 2). The levy might reduce CHD deaths in 2021 by approximately $7 \%$ among people aged $25-34$ years and $35-44$ years but by only $1 \%$ among people over 65 years old.

Changes in SSB intake under all scenarios would particularly benefit people of lower SEC. Estimated DPP in the most deprived group were almost twofold higher than the DPP in the most affluent (Table 3). The levy would also lead to approximately 1560 (95\% UI 680, 2630) LYG in the most deprived group and just 530 (95\% UI 230, 890) LYG in the most affluent, under a 'hard' Brexit scenario (Fig. 3).

\section{Discussion}

The present study estimated the potential implications of Brexit on the price of sugar and consequent impacts of the proposed SSB levy on CHD mortality and inequalities in England. The SSB levy may increase SSB prices by approximately $38 \%$ leading to an estimated $26 \%$ decrease in SSB intake. This would prevent approximately $370 \mathrm{CHD}$ deaths and generate approximately 4490 life-years in 2021. The SSB levy was associated with additional reductions in CHD mortality of 4 and $8 \%$ under 'soft' and 'hard' Brexit scenarios, respectively. The SSB levy would particularly benefit people in more deprived groups under both Brexit scenarios. This is attributed to the higher CHD mortality rates, higher SSB intake and higher sensitivity to SSB price changes among the more deprived. The persisting inequalities in CHD mortality in England despite rapid reductions at aggregate level ${ }^{(30)}$ highlight the importance of this finding.

The impact of trade regimes on health and national public health policies that aim to tackle diet-related chronic diseases remains under-investigated ${ }^{(31)}$. The present study is the first to quantify the potential impacts of Brexit on the SSB levy effectiveness through changes in the UK trade policy. Previous studies have suggested an association between trade agreements and SSB sales and intake. For example, a longitudinal analysis of forty-four low- and middle-income countries showed significant associations between tariffs on SSB and per capita imports and sales ${ }^{(32)}$. A systematic review identified an increase in 
(a)

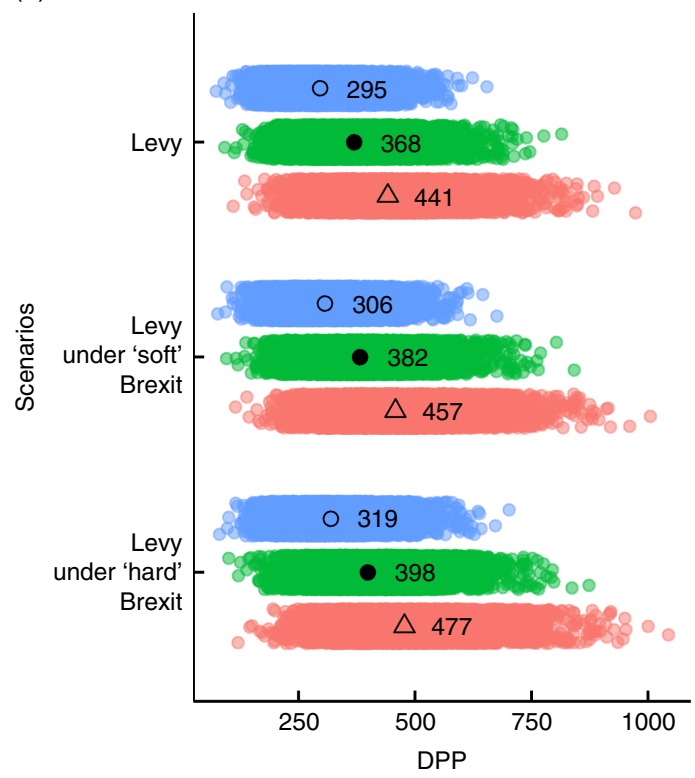

(b)

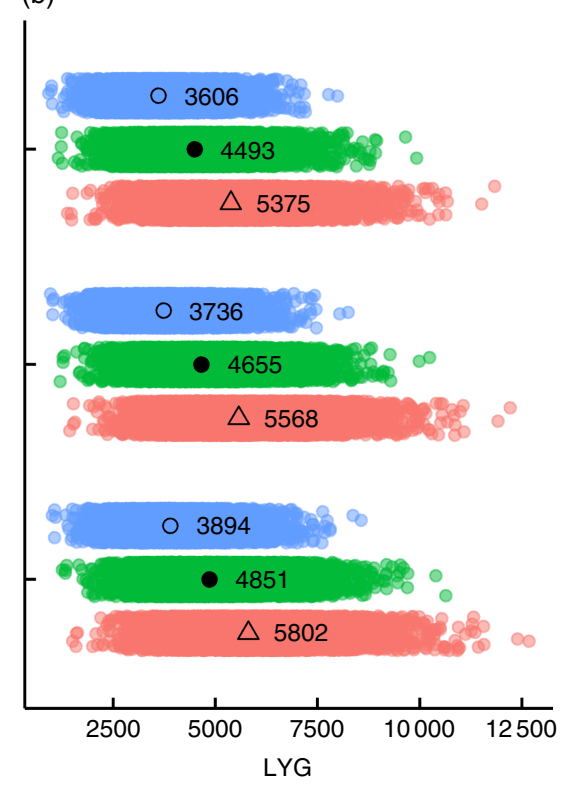

Fig. 1 (colour online) Effect of each scenario on the effectiveness of the UK soft drinks industry levy upon CHD in the English population aged 25 years or older, in 2021: (a) CHD deaths prevented or postponed (DPP); (b) CHD life-years gained (LYG). (, 0 ), $80 \%$ price pass-through; $(\odot, \odot), 100 \%$ price pass-through; $(\odot, \triangle), 120 \%$ price pass-through. Each point $(\odot, \circ, \odot)$ represents the DPP and LYG estimated from one iteration of the probabilistic analysis. The mean of 10000 iterations is noted for each scenario

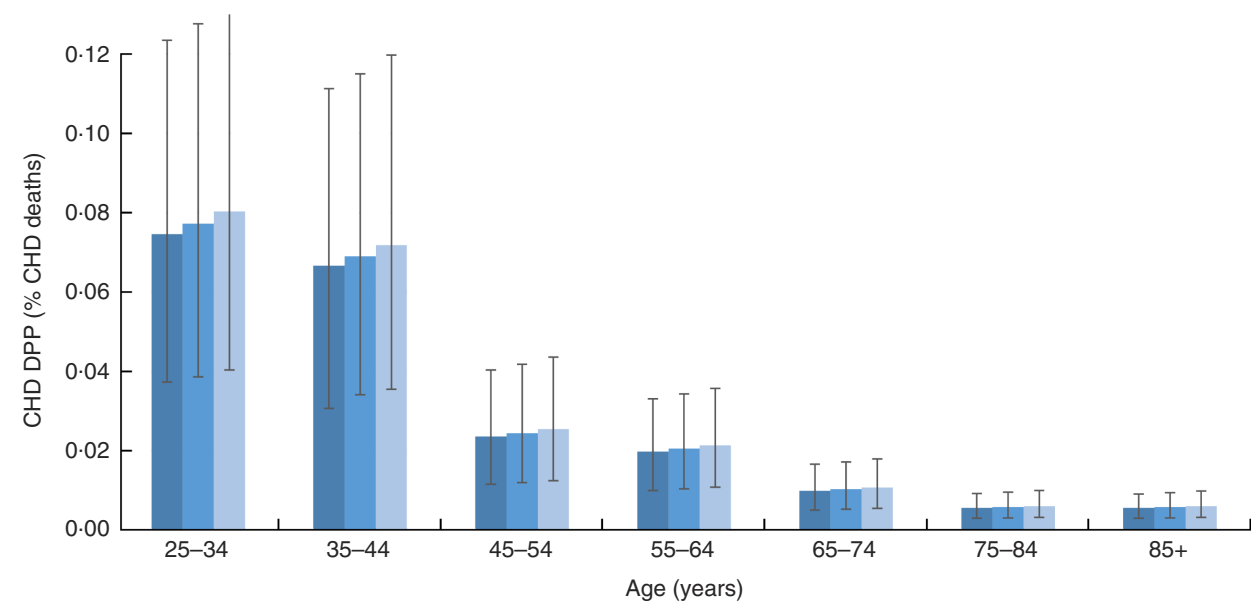

Fig. 2 (colour online) Age differential effect of each scenario ( $\square$, levy; $\square$, levy under 'soft' Brexit; $\square$, levy under 'hard' Brexit), in the case of $100 \%$ price pass-through, on the effectiveness of the UK soft drinks industry levy upon CHD deaths prevented or postponed (DPP), expressed as a percentage of baseline CHD deaths per age group, in the English population aged 25 years or older, in 2021. The vertical bars are $95 \%$ uncertainty intervals

sales and consumption of SSB in low- and middle-income countries after entering a trade agreement ${ }^{(31)}$. While the UK already has an established SSB industry operating domestically, SSB production relies heavily on sugar imports. Thus, changes in the trade regime are more likely to affect the UK SSB market indirectly through changes in the price of sugar, as modelled in the current analysis.

Our findings are reassuringly consistent with studies elsewhere. A quasi-experimental study concluded that abolition of import tariffs on beverage syrups, including high-fructose corn syrup, in Canada was significantly associated with an increase in their per capita energy supply ${ }^{(33)}$. However, the researchers did not investigate the consequent effect on beverages that incorporate highfructose corn syrup, like SSB. A modelling study in France suggested that a decrease in the price of sugar by $228 € / \mathrm{t}$, due to changes in the EU Common Agricultural Policy, could decrease SSB prices on average by $0.02 € / 1$, with high variation among different SSB brands ${ }^{(34)}$. These findings are consistent with our analysis which suggested that a sugar price reduction of 92 and $203 £ / t$ under a 'soft' and a 'hard' Brexit scenario would result in changes in the price of SSB of approximately 0.01 and $0.02 £ / 1$, respectively. 
Table 3 Effect of each scenario on the effectiveness of the UK soft drinks industry levy upon CHD deaths prevented or postponed (DPP) in the English population aged 25 years or older, stratified by Index of Multiple Deprivation (IMD) quintile, in 2021

\begin{tabular}{|c|c|c|c|c|c|c|}
\hline & \multicolumn{2}{|c|}{ SSB industry levy } & \multicolumn{2}{|c|}{ SSB industry levy under 'soft' Brexit } & \multicolumn{2}{|c|}{ SSB industry levy under 'hard' Brexit } \\
\hline & DPP & $95 \%$ UI & DPP & $95 \%$ UI & DPP & $95 \%$ UI \\
\hline \multicolumn{7}{|l|}{$80 \%$ pass-through } \\
\hline 1st IMD quintile (most affluent) & 41 & 17,72 & 43 & 18,74 & 44 & 19,77 \\
\hline 2nd IMD quintile & 49 & 21,85 & 50 & 21,88 & 53 & 22,92 \\
\hline 3rd IMD quintile & 52 & 22,90 & 54 & 23,93 & 56 & 24,97 \\
\hline 4th IMD quintile & 72 & 30,124 & 75 & 32,129 & 78 & 33,134 \\
\hline 5th IMD quintile (most deprived) & 81 & 35,139 & 84 & 36,144 & 88 & 37,150 \\
\hline Total & 295 & 176,446 & 306 & 183,461 & 319 & 190,481 \\
\hline \multicolumn{7}{|l|}{$100 \%$ pass-through } \\
\hline 1st IMD quintile (most affluent) & 51 & 22,89 & 53 & 23,93 & 56 & 23,97 \\
\hline 2nd IMD quintile & 61 & 26,106 & 63 & 27,110 & 66 & 28,114 \\
\hline 3rd IMD quintile & 65 & 27,112 & 67 & 28,116 & 70 & 30,121 \\
\hline 4th IMD quintile & 90 & 38,155 & 93 & 39,160 & 97 & 41,167 \\
\hline 5th IMD quintile (most deprived) & 101 & 43,173 & 105 & 45,179 & 109 & 47,186 \\
\hline Total & 368 & 220,556 & 382 & 228,575 & 398 & 237,600 \\
\hline \multicolumn{7}{|l|}{$120 \%$ pass-through } \\
\hline 1st IMD quintile (most affluent) & 62 & 26,107 & 64 & 27,111 & 67 & 28,116 \\
\hline 2nd IMD quintile & 73 & 31,126 & 75 & 32,131 & 79 & 33,137 \\
\hline 3rd IMD quintile & 78 & 33,135 & 81 & 34,139 & 84 & 36,145 \\
\hline 4th IMD quintile & 108 & 46,185 & 112 & 47,192 & 117 & 49,199 \\
\hline 5th IMD quintile (most deprived) & 121 & 52,207 & 126 & 54,214 & 131 & 56,223 \\
\hline Total & 441 & 264,666 & 457 & 273,689 & 477 & 285,718 \\
\hline
\end{tabular}

UI, uncertainty interval.

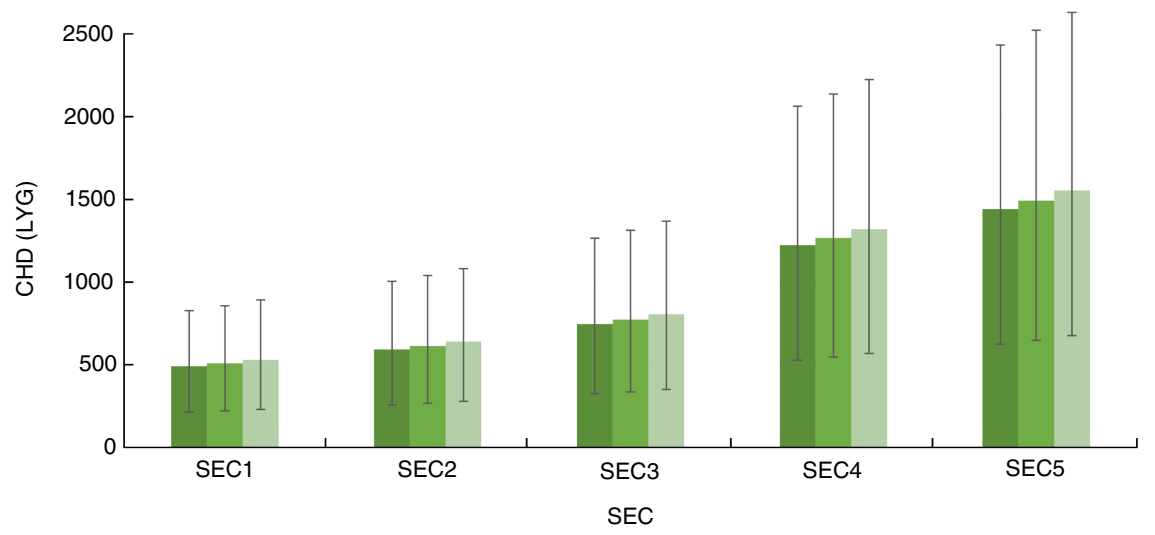

Fig. 3 (colour online) Socio-economic circumstance (SEC) differential effect of each scenario ( $\square$, levy; $\square$, levy under 'soft' Brexit; $\square$, levy under 'hard' Brexit), in the case of $100 \%$ price pass-through, on the effectiveness of the UK soft drinks industry levy upon CHD in terms of life-years gained (LYG) in the English population aged 25 years or older, in 2021. SEC1 is the most affluent group and SEC5 the most deprived. The vertical bars are $95 \%$ uncertainty intervals

We estimated an SSB price increase of approximately $30-46 \%$ due to the SSB levy, depending on the price passthrough to the consumer. This is higher than the SSB levy effect estimated in previous studies in other locations, due to differences in the implemented tax rates. For example, in Mexico, the applied excise tax represented approximately a $10 \%$ increase in SSB price ${ }^{(28)}$ and in Berkeley approximately $15 \%{ }^{(3)}$. However, we applied pass-through rates as observed in these jurisdictions. Variations of pass-through rates between types of SSB and points of sale were not taken into account, as our analysis investigated the SSB market overall.

Our analysis estimated that the SSB intake reduction due to the levy was associated with approximately 370 fewer deaths or a $1 \%$ reduction in estimated CHD mortality. A similar analysis in the USA found that a $10 \%$ SSB tax will result in approximately $0.4 \%$ reduction in CHD mortality ${ }^{(12)}$ over 15 years, while a modelling study in Mexico showed that a $20 \%$ reduction in SSB intake will result in approximately $2 \%$ reduction in CHD mortality over a period of 10 years ${ }^{(8)}$. These results are comparable to our one-year analysis as the authors assumed a sustained effect throughout the predicting period. The variation in the estimated results can be attributed in part to differences in the population intake of SSB and the magnitude of modelled interventions, as implemented SSB tax rates can vary significantly in different interventions.

The current analysis has a number of strengths. We used a previously validated food policy model ${ }^{(11-15)}$ which 
combines high-quality data, including detailed information on UK sugar trade, mortality projections that take declining trends in CHD mortality into account ${ }^{(20)}$ and nationally representative SSB intake data. It also enabled differential policy impacts between SEC groups to be modelled. Finally, uncertainty of inputs was incorporated into the model, using probabilistic sensitivity analysis.

However, there are some limitations that should also be considered. First, we used 2015 trade data to approximate sugar imports in 2021. We also used 2013 mortality and population data to adjust 2021 projections and assumed that CHD mortality and population differences between England and Wales and between SEC groups remained unchanged. The BAPC model also assumes that the age, period and cohort effects on mortality remain unchanged into the future, although it had the best predicted performance compared with conventional projections when validated $^{(20)}$. We assumed an immediate effect of SSB intake on $\mathrm{CHD}$, which might not be accurate. Moreover, we varied price effect estimates across SEC groups using SEC differential SSB purchase data after an SSB tax in Mexico $^{(2)}$. Those researchers found that the most deprived group was $65 \%$ more responsive to price change compared with the most affluent. Discrepancies in the inequality gap between Mexico and the UK might have overestimated the SEC differences in the current analysis; average real household net disposable income in the UK is roughly twice that of Mexico ${ }^{(35)}$. This model estimated the effects of the different scenarios on CVD only through CHD. Some evidence supports an SSB effect on stroke, mediated through BMI, mainly in overweight populations $^{(24)}$. However, we conservatively excluded SSB effects on stroke from the model. Finally, we modelled three different pass-through rates to investigate the industry response to the SSB levy and Brexit effects, based on industry responses to SSB taxes and sugar price increases elsewhere. However, the industry might have additional responses to the levy, such as product reformulation and shifts in the market shares of mid- and highsugar $\mathrm{SSB}^{(36)}$. For the current analysis, we estimated a single pooled levy rate based on the market distribution before the levy implementation, assuming it will stay unchanged until 2021.

The model did not directly account for substitutability of SSB with other foods or beverages as has been conducted in previous work ${ }^{(37)}$. This is because the estimates of price responsiveness used in our study were drawn from a meta-analysis of longitudinal studies which reflects actual dietary changes after a change in the price of SSB, accounting for substitutability and complementarity in real-world settings. Another advantage of these estimates is that they specifically investigate the effect of a price increase of SSB taking account of the direction of the price change. However, they did not account for the potential effect of the change in SSB price on the intake of other beverages. Observational data from Mexico ${ }^{(2)}$ suggest that the increase in untaxed beverages that followed the SSB tax implementation was mainly driven by an increase in bottled water, which is not likely to have significant effects on health outcomes. Finally, any unmeasured effects due to changes in the intake of other foods and beverages are likely to be consistent across the different scenarios modelled. Thus, we assumed that taking account of these effects would not significantly alter our conclusions.

The present study provides a first estimation of the potential effect of Brexit on the SSB industry levy in the UK and represents an important example for future research in this area. We conservatively quantified the potential effect of Brexit on the price of sugar only one year after the post-Brexit transitional period due to the complexities and uncertainties following Brexit in the medium and long terms. For example, the UK is unlikely to conclude preferential trading agreements with third countries immediately after the two-year transitional period, due to the extensive time that these negotiations commonly take to complete. However, in the long term, the UK could establish preferential trading agreements with competitive partners, such as Australia and Brazil ${ }^{(10)}$, which would allow an inflow of cheap sugar into the UK market. These changes are attractive to UK lobbying groups, such as the sugarcane refining industry, parts of which have been vocally in favour of Brexit ${ }^{(38)}$. Also, in the long term, the SSB industry might decide to shift towards domestically produced sugar, encouraging British farmers to increase their production to meet demand. In this model, we assumed that industry will maintain the current market split between imported and domestically produced sugar, given the time needed to achieve such a change.

Further studies could also evaluate potential effects of Brexit on the industry response to the SSB levy. We found that Brexit will probably cost the industry millions of pounds in ingredient expenses that might encourage product reformulation with reduction of sugar content in SSB. A previous investigation of industry responses to the UK SSB levy suggested that product reformulation could be the most beneficial result in terms of improving health outcomes $^{(36)}$. However, Brexit might allow the industry to shift towards alternative sweeteners, like high-fructose corn syrup. This would be highly affected by the postBrexit agricultural regime. Currently, the Common Agricultural Policy is in place for all EU countries, including the UK. Under the Common Agricultural Policy, sugar price was kept high using production quotas and minimum price guarantees, while production of high-fructose corn syrup was restricted, accounting for $3.5 \%$ of the EU sweetener market ${ }^{(19)}$. The EU liberalised its sugar agricultural regime in October 2017 by removing these restrictions. This is likely to affect price and availability of sugar and high-fructose corn syrup and encourage their incorporation in $\mathrm{SSB}^{(39)}$. Should the UK adopt a similar liberalised agricultural regime for sugar post-Brexit, the 
costs for the SSB industry might drop, making SSB production more profitable and allowing the industry to resist public health initiatives, like the SSB industry levy.

Brexit may also have wider implications on the SSB industry and prices, which go beyond the price of sugar. For example, Brexit is likely to affect the UK food system as a whole, causing disruptions across the whole supply chain $^{(40)}$. Changes in costs of packaging, distribution and retailing of SSB may further affect SSB consumer prices. Moreover, the food and beverage industry in the UK relies heavily on the EU workforce, with almost a third of its workers being EU citizens ${ }^{(41)}$. Restrictions in the movement of labour between the UK and the EU might burden the SSB industry with a significant labour shortage. Lastly, the SSB industry will not be exempted from the overall macroeconomic effects of Brexit in the UK economy, both in the short term ${ }^{(42)}$ and the long term ${ }^{(43)}$.

Finally, the significant increases in sugar price due to Brexit estimated in the current analysis may raise concerns about the effect of Brexit on other food commodities. For example, the UK is dependent on EU and third country imports for its fruit and vegetable supply ${ }^{(18)}$. Steep increases in fruit and vegetable prices post-Brexit might reduce their consumption with detrimental implications to public health, especially among low-income populations.

\section{Conclusion}

Our study suggests that the UK SSB industry levy is likely to be resilient to potential Brexit effects on sugar price due to changes in the UK trade regime, even if trade occurs under WTO regulations. It also suggests that even under alternative Brexit scenarios the SSB levy is likely to remain progressive in terms of CHD inequalities. Brexit presents a crucial opportunity to achieve a healthier food system in the UK if negotiations deliver a fiscal and regulatory environment which promotes population health.

\section{Acknowledgements}

Acknowledgements: The Public Health Policy Evaluation Unit is grateful for the support of the National Institute for Health Research (NIHR) School of Public Health Research. Financial support: P.S., A.A.L. and C.M. are funded by NIHR via a Research Professorship Award (C.M., grant number RP 2014-04-032). NIHR had no role in the design, analysis or writing of this article. Conflict of interest: None. Authorship: P.S., A.A.L., J.P.-S., M.O.F. and C.M. conceived and designed the study. P.S. implemented the model and drafted the paper with inputs from all authors. All authors made a substantial contribution to the data interpretation and critical review of the submitted manuscript. Ethics of buman subject participation: Not applicable.

\section{Supplementary material}

To view supplementary material for this article, please visit https://doi.org/10.1017/S1368980018002367

\section{References}

1. World Health Organization (2016) Report of the Commission on Ending Childhood Obesity. Geneva: WHO.

2. Colchero MA, Popkin BM, Rivera JA et al. (2016) Beverage purchases from stores in Mexico under the excise tax on sugar sweetened beverages: observational study. BMJ 352, h6704.

3. Silver LD, Ng SW, Ryan-Ibarra S et al. (2017) Changes in prices, sales, consumer spending, and beverage consumption one year after a tax on sugar-sweetened beverages in Berkeley, California, US: a before-and-after study. PLoS Med 14, e1002283.

4. Falbe J, Thompson HR, Becker CM et al. (2016) Impact of the Berkeley excise tax on sugar-sweetened beverage consumption. Am J Public Health 106, 1865-1871.

5. Mozaffarian D, Hao T, Rimm EB et al. (2011) Changes in diet and lifestyle and long-term weight gain in women and men. N Engl J Med 364, 2392-2404.

6. Imamura F, O'Connor L, Ye Z et al. (2015) Consumption of sugar sweetened beverages, artificially sweetened beverages, and fruit juice and incidence of type 2 diabetes: systematic review, meta-analysis, and estimation of population attributable fraction. BMJ 351, h3576.

7. Xi B, Huang Y, Reilly KH et al. (2015) Sugar-sweetened beverages and risk of hypertension and CVD: a doseresponse meta-analysis. BrJ Nutr 113, 709-717.

8. Sanchez-Romero LM, Penko J, Coxson PG et al. (2016) Projected impact of Mexico's sugar-sweetened beverage tax policy on diabetes and cardiovascular disease: a modeling study. PLoS Med 13, e1002158.

9. HM Government (2016) Childhood Obesity. A Plan for Action. London: HM Government; available at https://www. gov.uk/government/publications/childhood-obesity-a-planfor-action

10. Swinbank A (2017) World Trade Rules and the Policy Options for British Agriculture Post-Brexit. Briefing Paper 7. Falmer, UK: UK Trade Policy Observatory, University of Sussex; available at http://blogs.sussex.ac.uk/uktpo/files/2017/01/ Briefing-paper-7.pdf

11. O'Flaherty M, Flores-Mateo G, Nnoaham K et al. (2012) Potential cardiovascular mortality reductions with stricter food policies in the United Kingdom of Great Britain and Northern Ireland. Bull World Health Organ 90, 522-531.

12. Pearson-Stuttard J, Bandosz P, Rehm CD et al. (2017) Reducing US cardiovascular disease burden and disparities through national and targeted dietary policies: a modelling study. PLoS Med 14, e1002311.

13. Allen K, Pearson-Stuttard J, Hooton W et al. (2015) Potential of trans fats policies to reduce socioeconomic inequalities in mortality from coronary heart disease in England: cost effectiveness modelling study. BMJ 351, h4583.

14. Pearson-Stuttard J, Critchley J, Capewell S et al. (2015) Quantifying the socio-economic benefits of reducing industrial dietary trans fats: modelling study. PLoS One 10, e0132524.

15. Pearson-Stuttard J, Hooton W, Critchley J et al. (2017) Costeffectiveness analysis of eliminating industrial and all trans fats in England and Wales: modelling study. J Public Health (Oxf) 39, 574-582.

16. Unal B, Critchley JA \& Capewell S (2004) Explaining the decline in coronary heart disease mortality in England and 
Wales between 1981 and 2000. Circulation 109, 11011107.

17. HM Revenue \& Customs (2017) UK Trade Statistics. https:// www.uktradeinfo.com/ (accessed February 2017).

18. Department for Environment Food \& Rural Affairs (2017) Agriculture in the United Kingdom 2016. London: DEFRA; available at https://www.gov.uk/government/statistics/ agriculture-in-the-united-kingdom-2016

19. European Commission (2016) EU Agricultural Outlook. Prospects for EU agricultural markets and income 20162026. https://ec.europa.eu/agriculture/sites/agriculture/ files/markets-and-prices/medium-term-outlook/2016/2016fullrep_en.pdf (accessed September 2018).

20. Guzman Castillo M, Gillespie DOS, Allen K et al. (2014) Future declines of coronary heart disease mortality in England and Wales could counter the burden of population ageing. PLoS One 9, e99482.

21. Office for National Statistics (2014) Number of registered deaths by sex, cause, year, the Adjusted Index of Multiple Deprivation 2010 quintiles (fifths) of Lower Super Output Areas and age group, England, 2002 to 2013. http://www. ons.gov.uk/ons/about-ons/business-transparency/freedomof-information/what-can-i-request/published-ad-hoc-data/ health/december-2014/number-of-registered-deaths-by-sex-cause--year--the-adjusted-index.xls (accessed January 2017).

22. Afshin A, Peñalvo JL, Del Gobbo L et al. (2017) The prospective impact of food pricing on improving dietary consumption: a systematic review and meta-analysis. PLoS One 12, e0172277.

23. NatCen Social Research, MRC Human Nutrition Research \& University College London Medical School (2015) National Diet and Nutrition Survey Years 1-4, 2008/09-2011/12, 7th ed. http://dx.doi.org/10.5255/UKDA-SN-6533-6 (accessed September 2018).

24. Micha R, Peñalvo JL, Cudhea F et al. (2017) Association between dietary factors and mortality from heart disease, stroke, and type 2 diabetes in the united states. JAMA 317, 912-924.

25. British Soft Drinks Association (2017) Making it Happen. Annual report 2017, http://www.britishsoftdrinks.com/ write/MediaUploads/Publications/BSDA_Drinks_Report_2017. pdf (accessed September 2018).

26. HM Government (2017) The United Kingdom's exit from and new partnership with the European Union. https://www. gov.uk/government/publications/the-united-kingdoms-exitfrom-and-new-partnership-with-the-european-union-whitepaper (accessed September 2018).

27. Euromonitor International (2015) Market research provider. http://www.euromonitor.com (accessed October 2016).

28. Colchero MA, Salgado JC, Unar-Munguia M et al. (2015) Changes in prices after an excise tax to sweetened sugar beverages was implemented in Mexico: evidence from urban areas. PLoS One 10, e0144408.

29. Howell D, Lowthian E, Bulman J et al. (2015) Family spending: 2015. A report on the Living Costs and Food Survey 2014. https://www.ons.gov.uk/peoplepopulationand community/personalandhouseholdfinances/incomeandwealth/ compendium/familyspending/2015 (accessed September 2018).
30. Pearson-Stuttard J, Bajekal M, Scholes S et al. (2012) Recent UK trends in the unequal burden of coronary heart disease. Heart 98, 1573-1582.

31. Barlow P, McKee M, Basu S et al. (2017) The health impact of trade and investment agreements: a quantitative systematic review and network co-citation analysis. Global Health 13, 13.

32. Mendez Lopez A, Loopstra R, McKee M et al. (2017) Is trade liberalisation a vector for the spread of sugar-sweetened beverages? A cross-national longitudinal analysis of 44 lowand middle-income countries. Soc Sci Med 172, 21-27.

33. Barlow P, McKee M, Basu S et al. (2017) Impact of the North American Free Trade Agreement on high-fructose corn syrup supply in Canada: a natural experiment using synthetic control methods. CMAJ 189, E881-E887.

34. Bonnet C \& Requillart V (2011) Does the EU sugar policy reform increase added sugar consumption? An empirical evidence on the soft drink market. Health Econ 20, 1012-1024.

35. Organisation for Economic Cooperation and Development (2017) Household disposable income (indicator). https://data. oecd.org/hha/household-disposable-income.htm (accessed July 2017).

36. Briggs ADM, Mytton OT, Kehlbacher A et al. (2016) Health impact assessment of the UK soft drinks industry levy: a comparative risk assessment modelling study. Lancet Public Health 2, e15-e22.

37. Dharmasena S \& Capps O Jr (2012) Intended and unintended consequences of a proposed national tax on sugarsweetened beverages to combat the US obesity problem. Health Econ 21, 669-694.

38. Tate \& Lyle Sugars (2016) Brexit: a golden opportunity. http:// www.brexitgoldenopportunity.com/ (accessed April 2017).

39. Aguirre EK, Mytton OT \& Monsivais P (2015) Liberalising agricultural policy for sugar in Europe risks damaging public health. BMJ 351, h5085.

40. Lang T, Millstone E \& Marsden T (2017) A Food Brexit: Time to Get Real. A Brexit Briefing Paper. Falmer, UK: Science Policy Research Unit, University of Sussex; available at https://www.sussex.ac.uk/webteam/gateway/file.php?name= foodbrexitreport-langmillstonemarsden-july2017pdf.pdf\&site $=$ 25

41. Heasman M \& Morley A (2017) Earning a Crust? A review of labour trends in UK food manufacturing. Food Research Collaboration Policy Brief. http://foodresearch.org.uk/wpcontent/uploads/2017/05/Earning-A-Crust-A-review-of-labourtrends-in-UK-manufacturing-Briefing-Paper-2017.pdf (accessed September 2018).

42. HM Government (2016) HM Treasury analysis: the immediate economic impact of leaving the EU. https://www.gov.uk/ government/publications/hm-treasury-analysis-the-immediateeconomic-impact-of-leaving-the-eu (accessed September 2018).

43. HM Government (2016) HM Treasury analysis: the long-term economic impact of EU membership and the alternatives. https://www.gov.uk/government/publications/hm-treasuryanalysis-the-long-term-economic-impact-of-eu-membershipand-the-alternatives (accessed September 2018). 